\title{
Stochastic finite element analysis of long-span bridges with CFRP cables under earthquake ground motion
}

\author{
ÖZLEM ÇAVDAR ${ }^{1, *}$, ALEMDAR BAYRAKTAR $^{2}$, \\ SÜLEYMAN ADANUR ${ }^{2}$ and HASAN BASRI BAŞAĞA ${ }^{2}$ \\ ${ }^{1}$ Gümüşhane University, Department of Civil Engineering, 29000, Gümüşhane, \\ Turkey \\ ${ }^{2}$ Karadeniz Technical University, Department of Civil Engineering, 61080, \\ Trabzon, Turkey \\ e-mail: ozlem_cavdar@hotmail.com; alemdar@ktu.edu.tr; sadanur@ktu.edu.tr; \\ hasanbb69@hotmail.com
}

MS received 18 May 2009; revised 5 November 2009; accepted 16 March 2010

\begin{abstract}
Stochastic seismic analysis of long-span bridges with Carbon fibre reinforced polymer (CFRP) cables are presented in this study through combination of the advantages of the perturbation based stochastic finite element method (SFEM) and Monte Carlo simulation (MCS) method. Jindo cable-stayed and Fatih Sultan Mehmet (Second Bosporus) suspension bridges are chosen as an example. Carbon fibre reinforced polymer cable (CFRP) and steel cables are used separately, in which the cable's cross sectional area is determined by the principle equivalent axial stiffness. Geometric nonlinear effects are considered in the analysis. Uncertainties in the material are taken into account and Kocaeli earthquake in 1999 is chosen as a ground motion. The efficiency and accuracy of the proposed algorithm are validated by comparing with results of MCS method. It can be stated that using of CFRP cables in long-span bridges subjected to earthquake forces is feasible.
\end{abstract}

Keywords. Cable-supported bridges; suspension bridges; carbon fibre reinforced polymer (CFRP) cable; stochastic finite element method (SFEM); random variable; Monte Carlo simulation (MCS) method.

\section{Introduction}

The stay cables for cable-stayed bridges, and main cables and hangers for suspension bridges are the main structural elements and they have significant influences on structural performance and appearance. The cables in long-span bridges are subjected to tension induced by the dead and live loads. The tensile strength of the cables is one of the most important mechanical properties of the long-span bridges (Kremmidas 2004). Unlike many other bridge types, these components are completely exposed to environmental conditions. It is thus of general interest

*For correspondence 
to make such cables as corrosion resistant as possible. Continuous attempts are being made to improve the traditional cable's materials, at the same time engineers and researchers are trying to develop new engineering materials. Among them, more attentions are given to the CFRP material. Advanced composites such as CFRP offer properties like high specific strength, stiffness, high fatigue and excellent chemical resistance. These outstanding properties make them prime candidates for bridge applications such as cable, hanger or conventional box girder structures (Almansour 2006).

The first application of CFRP as cables in a real long-span bridge is in a road bridge, which crosses several railway tracks in Winterthur, Switzerland in 1996, among the twenty-four cables, two are made of CFRP, while the rest are the conventional steel cables (Cheng 1999). The feasibility of using CFRP cables in long-span bridges attracts increasing attentions from civil engineers. The slender and flexible characteristics of the long-span bridge make it sensitive to the dynamic loads. The adoption of CFRP cables, which has different properties from the conventional steel cables, may significantly affect the dynamic response of the bridges. Researches on the impact of using CFRP cables in bridges have been conducted (Zhang \& Ying 2007; Khalifa 1992; Meirer 1999; Noisternig 2000; Zhang \& Chai 2007; Aparicio \& Casas 1997). These studies were based on the assumption of complete determinacy of structural parameters. This is usually referred to as deterministic analysis. In reality, however, there are uncertainties in design variables. These uncertainties include geometric properties, material mechanical properties, load magnitude and distribution, etc. Therefore, deterministic analysis cannot provide complete information regarding dynamic responses of long-span bridges with cables.

To identify changes in the material and geometrical properties of a bridge, stochastic finite element method (SFEM) is required (Kleiber \& Hien 1992; Falsone \& Impollonia 2002; Çavdar et al 2008; Adhikari \& Friswell 2007; Zhu \& Wu 1992; Adhikari \& Manohar 2000). Very few researchers (Cheng \& Xiao 2005; Liu et al 1999) studied the SFEM with random variable material and geometrical properties of long-span bridges having steel cables. Cheng \& Xiao (2005), proposed a stochastic finite-element-based algorithm for the probabilistic free vibration and flutter analyses of suspension bridges. Liu et al (1999) investigated large-flexible structures, such as suspension bridges, actually possess stochastic material properties and these random properties unavoidably affect the dynamic system parameters.

The focus of the present paper is to perform the stochastic seismic analysis of long-span cable-stayed and suspension bridges using either steel or CFRP cables. In this work, Jindo Bridge, a cable-stayed bridge using CFRP stay cables, and Fatih Sultan Mehmet (Second Bosporus) Bridge, a suspension bridge using CFRP cables and hangers, are chosen as numerical examples. During stochastic analysis, modal frequencies, displacements and internal forces of the long-span bridges are obtained from perturbation-based SFEM by using different uncertainties of material characteristics. Elastic modulus is chosen as random variable material properties. The analysis results obtained from using either CFRP or steel cables according to perturbation based SFEM are compared with each other. In addition, the efficiency and accuracy of the proposed algorithm are validated by comparing with displacement results of MCS method.

\section{Stochastic formulation}

There are two fundamental ways to solve the stochastic problem; (i) analytical approach and (ii) numerical approach. Among analytical approaches, the perturbation-based SFEM is 
widely used because of its simplicity. Numerical method such as Monte Carlo Simulation (MCS) is generally applicable to all types of stochastic problems and is often used to verify the results obtained from analytical methods. A detailed discussion of these methods is presented below.

\subsection{Perturbation-based SFEM formulation}

The perturbation method is the most widely used technique for analysing uncertain system. The basic idea behind the perturbation method is to express the stiffness and mass matrices and the responses in terms of Taylor series expansion with respect to the parameters centered at the mean values (Kleiber \& Hien 1992).

Let us consider a deterministic equation of motion in the form of

$$
M_{\alpha \beta} \ddot{q}_{\beta}+C_{\alpha \beta} \dot{q}_{\beta}+K_{\alpha \beta} q_{\beta}=Q_{\alpha},
$$

where $K_{\alpha \beta}, M_{\alpha \beta}, C_{\alpha \beta}$ denote the stiffness matrix, mass matrix and damping matrix, $\ddot{q}_{\beta}, \dot{q}_{\beta}, q_{\beta}$ denote the acceleration, velocity, displacement, respectively.

The stochastic perturbation-based approach usually consists of up to the second order equations obtained starting from the deterministic ones. The perturbation stochastic finite element equations describing dynamic response of random variable system for the zeroth, first and second order are given below:

Zeroth-order equation $\left(\epsilon^{0}\right.$ terms, one system of $N$ linear simultaneous ordinary differential equations for $\left.q_{\alpha}^{0}\left(b_{l}^{0} ; \tau\right), \alpha=1,2, \ldots, N\right)$

$$
M_{\alpha \beta}^{0}\left(b_{l}^{0}\right) \ddot{q}_{\beta}^{0}\left(b_{l}^{0} ; \tau\right)+C_{\alpha \beta}^{0}\left(b_{l}^{0}\right) \dot{q}_{\beta}^{0}\left(b_{l}^{0} ; \tau\right)+K_{\alpha \beta}^{0}\left(b_{l}^{0}\right) q_{\beta}^{0}\left(b_{l}^{0} ; \tau\right)=Q_{\alpha}^{0}\left(b_{l}^{0} ; \tau\right) .
$$

First-order equations, rewritten separately for all random variables of the problem $\left(\epsilon^{1}\right.$ terms, $\bar{N}$ systems of $N$ linear simultaneous ordinary differential equations for $q_{\alpha}^{, \rho}\left(b_{l}^{0} ; \tau\right), \rho=$ $1,2, \ldots, \bar{N}, \alpha=1,2, \ldots, N)$

$$
\begin{gathered}
M_{\alpha \beta}^{0}\left(b_{l}^{0}\right) \ddot{q}_{\beta}^{, \rho}\left(b_{l}^{0} ; \tau\right)+C_{\alpha \beta}^{0}\left(b_{l}^{0}\right) \dot{q}_{\beta}^{, \rho}\left(b_{l}^{0} ; \tau\right)+K_{\alpha \beta}^{0}\left(b_{l}^{0}\right) q_{\beta}^{, \rho}\left(b_{l}^{0} ; \tau\right)=Q_{\alpha}^{, \rho}\left(b_{l}^{0} ; \tau\right) \\
-\left[M_{\alpha \beta}^{, \rho}\left(b_{l}^{0}\right) \ddot{q}_{\beta}^{0}\left(b_{l}^{0} ; \tau\right)+C_{\alpha \beta}^{, \rho}\left(b_{l}^{0}\right) \dot{q}_{\beta}^{0}\left(b_{l}^{0} ; \tau\right)+K_{\alpha \beta}^{, \rho}\left(b_{l}^{0}\right) q_{\beta}^{0}\left(b_{l}^{0} ; \tau\right)\right] .
\end{gathered}
$$

Second-order $\left(\epsilon^{2}\right.$ terms, one system of $N$ linear simultaneous ordinary differential equations for $\left.q_{\alpha}^{2}\left(b_{l}^{0} ; \tau\right), \alpha=1,2, \ldots, N\right)$

$$
\begin{aligned}
& M_{\alpha \beta}^{0}\left(b_{l}^{0}\right) q_{\beta}^{, \rho}\left(b_{l}^{0} ; \tau\right)+C_{\alpha \beta}^{0}\left(b_{l}^{0}\right) q_{\beta}^{, \rho}\left(b_{l}^{0} ; \tau\right)+K_{\alpha \beta}^{0}\left(b_{l}^{0}\right) q_{\beta}^{, \rho}\left(b_{l}^{0} ; \tau\right) \\
& \quad=\left\{Q_{\alpha}^{, \rho \sigma}\left(b_{l}^{0} ; \tau\right)-2\left[M_{\alpha \beta}^{, \rho}\left(b_{l}^{0}\right) q_{\beta}^{, \sigma}\left(b_{l}^{0} ; \tau\right)+C_{\alpha \beta}^{, \rho}\left(b_{l}^{0}\right) q_{\beta}^{, \sigma}\left(b_{l}^{0} ; \tau\right)+K_{\alpha \beta}^{, \rho}\left(b_{l}^{0}\right) q_{\beta}^{, \sigma}\left(b_{l}^{0} ; \tau\right)\right]\right. \\
& \left.\quad-\left[M_{\alpha \beta}^{, \rho \sigma}\left(b_{l}^{0}\right) q_{\beta}^{0}\left(b_{l}^{0} ; \tau\right)+C_{\alpha \beta}^{, \rho \sigma}\left(b_{l}^{0}\right) q_{\beta}^{0}\left(b_{l}^{0} ; \tau\right)+K_{\alpha \beta}^{, \rho \sigma}\left(b_{l}^{0}\right) q_{\beta}^{0}\left(b_{l}^{0} ; \tau\right)\right]\right\} \operatorname{Cov}\left(b_{r}, b_{s}\right),
\end{aligned}
$$

where $b_{\ell}^{0}$ is the vector of nodal random variables, $q_{\alpha}$ is the vector of nodal displacement-type variables, $\tau$ is forward time variable, $\bar{N}$ is the number of nodal random variables. $M_{\alpha \beta}^{0}, C_{\alpha \beta}^{0}$ and $K_{\alpha \beta}^{0}$ are system mass matrix, damping matrix and system stiffness matrix, respectively. $Q_{\alpha}^{0}, q_{\beta}^{0}$ and $\operatorname{Cov}\left(b_{r}, b_{s}\right)$ are load vector, displacement and the covariance matrix of the nodal random variable, respectively. $N$ is the number of degrees of freedom in the system. (. $)^{0}$ is zeroth-order quantities, taken at means of random variables, (.), ${ }^{\rho}$ is first partial derivatives 
with respect to nodal random variables, (.) ${ }^{, \rho \sigma}$ is second partial derivatives with respect to nodal random variables.

The first two statistical moments for the random fields $b_{r}\left(x_{k}\right), r=1,2, \ldots, R$, are defined as (Kleiber \& Hien 1992)

$$
\begin{aligned}
& E\left[b_{r}\right]=b_{r}^{0}=\int_{-\infty}^{+\infty} b_{r} p_{1}\left(b_{r}\right) d b_{r} \\
& \operatorname{Cov}\left(b_{r}, b_{s}\right)=S_{b}^{r s}=\int_{-\infty}^{+\infty} \int_{-\infty}^{+\infty}\left(b_{r}-b_{r}^{0}\right)\left(b_{s}-b_{s}^{0}\right) p_{2}\left(b_{r}, b_{s}\right) d b_{r} d b_{s} \quad r, s=1,2, \ldots, R .
\end{aligned}
$$

The latter definition can be replaced by [1],

$$
S_{b}^{r s}=\alpha_{b_{r}} \alpha_{b_{s}} b_{r}^{0} b_{s}^{0} \mu_{b_{r} b_{s}}
$$

with

$$
\alpha_{b_{r}}=\left[\frac{\operatorname{Var}\left(b_{r}\right)}{b_{r}^{0}}\right]^{1 / 2} \mu_{b_{r} b_{s}}=\int_{-\infty}^{+\infty} \int_{-\infty}^{+\infty} b_{r} b_{s} p_{2}\left(b_{r}, b_{s}\right) d b_{r} d b_{s},
$$

where, $E\left[b_{r}\right], \operatorname{Cov}\left(b_{r}, b_{s}\right), \operatorname{Var}\left(b_{r}\right)$ are the spatial expectation value, covariance and variance, respectively; $\mu_{b_{r} b_{s}}, \alpha_{b_{r}}, p_{1}\left(b_{r}\right)$ are correlation functions, the coefficients of variation and probability density function (PDF), respectively. $p_{2}\left(b_{r}, b_{s}\right)$ is the joint PDF. $R$ is the random fields, which can represent randomness elastic modulus, and mass density of the material, etc.

All the equations, solved consequently for zeroth, first and second order displacements, velocities and accelerations, make it possible to compute the first two probabilistic moments of the output in the form of expected values and cross-covariances of the structural response.

\subsection{Monte carlo simulation (MCS) method}

The Monte Carlo Simulation generates a set of random values of $X$ according to its probability distribution function. The set can be written as $X=\left\{x_{1}, x_{2}, \ldots, x_{N}\right\}$, where $N$ is the number of simulation. For each values of $X$, the stiffness and mass matrices are computed. At the end of $N$ simulations, we have a random set of displacement and stress values $\left\{\left\{q_{\beta}\right\}_{1},\left\{q_{\beta}\right\}_{2},\left\{q_{\beta}\right\}_{3}, \ldots,\left\{q_{\beta}\right\}_{N}\right\},\left\{\{\sigma\}_{1},\{\sigma\}_{2},\{\sigma\}_{3}, \ldots,\{\sigma\}_{N}\right\}$ for $X_{i}$. From this finite set of solutions, the expected values of displacement and stress are computed using the following formulas (Shinozuka 1972; Zhang \& Ellingwood 1996; Melchers 1999):

$$
\begin{gathered}
E_{\left\{q_{\beta}\right\}}=\frac{1}{N} \sum_{i=1}^{N}\left\{q_{\beta}\right\}_{i}, \\
E_{\{\sigma\}}=\frac{1}{N} \sum_{i=1}^{N}\{\sigma\}_{i} .
\end{gathered}
$$

\section{Numerical applications}

A cable-stayed bridge and a suspension bridge with steel and CFRP cables are considered as examples. The elastic modulus was chosen as random variable for both examples. Coefficients 


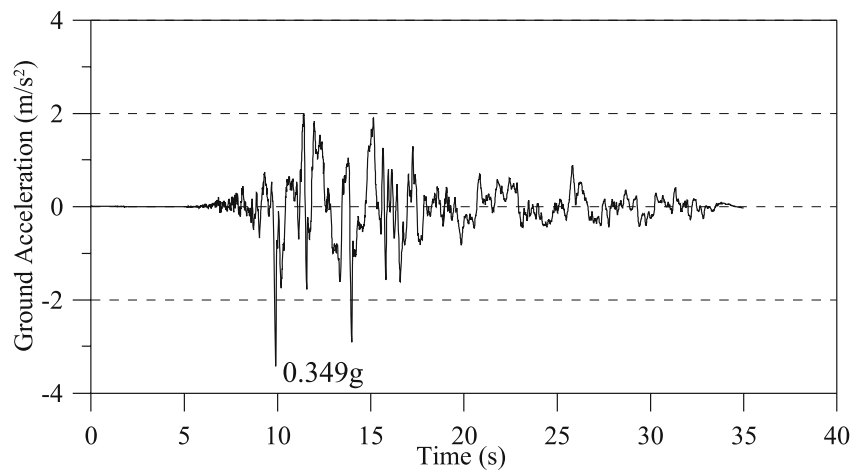

Figure 1. Acceleration time history of Kocaeli earthquake (YPT330) in 1999 (Peer 2007).

of variation (COV) of two materials differ from each other. This value for steel is about $10 \%$ $[3,20]$, on the other hand, for CFRP, this value is about $15 \%$ (Brunner 2000).

The cross-section areas of CFRP stay cables for the bridge examples are determined by the equivalent axial stiffness, and calculated by the following equation (Cheng 1999):

$$
E_{\mathrm{CFRP}} A_{\mathrm{CFRP}}=E_{\mathrm{STEEL}} A_{\mathrm{STEEL}},
$$

where $\mathrm{E}_{\mathrm{CFRP}}, \mathrm{E}_{\mathrm{STEEL}}$ are the elastic modulus of CFRP and steel, respectively; $\mathrm{A}_{\mathrm{CFRP}}, \mathrm{A}_{\mathrm{STEEL}}$ are the cross-sectional areas of CFRP and steel cables, respectively.

For stochastic dynamic analyses of the bridge models, the YPT330 component of the August 17, 1999, Kocaeli, Turkey earthquake is chosen as shown in figure 1 . The earthquake motion continued up to $35.0 \mathrm{~s}$ is applied to the cable-supported bridges in a vertical direction. The dynamic responses of the cable-supported bridges are obtained for a time interval of $0.005 \mathrm{~s}$ using the mode superposition method considering Wilson- $\theta$ algorithm.

\subsection{Example 1. Cable-stayed bridge}

Jindo Bridge built in South Korea is chosen as a practical example to investigate stochastic response of a cable-stayed bridge using either CFRP or steel stay cables. Jindo Bridge has three spans, the main span of $344 \mathrm{~m}$ and two side spans of $70 \mathrm{~m}$, as shown in figure 2 . The stays are arranged in a fan configuration and converged at the top of the A-frame towers. The diameters of the stays are $56 \mathrm{~mm}, 67 \mathrm{~mm}, 76 \mathrm{~mm}$ and $87 \mathrm{~mm}$. Each carries 24 stays and the towers are $69 \mathrm{~m}$ height above the piers on which they are supported. The chosen finite element model is represented by 420 degrees of freedom. As the stiffening girder and towers are represented by 139 beam elements, the cable stays are modelled with 30 truss elements. The stiffening girder and the towers of the Jindo Bridge were made of steel (Tappin \& Clark 1985). For the purpose of discussion, a same span length of cable-stayed bridge with CFRP stay cables is schemed. Except for the material and sectional properties of the cables, other design parameters of the Jindo Bridges are remained the same. The cable's cross sectional area is determined by the principle equivalent axial stiffness in equation (11). Structural material and sectional properties of the steel and CFRP cables are presented in table 1.

Damping coefficients of CFRP composite structures are higher than those for typical steel structures (Almansour 2006). Therefore, a damping ratio of $2 \%$ is adopted for the response calculations of cable-stayed bridge consist of steel cables. Damping ratio 5\% of is utilized for the CFRP composite bridge model through the stochastic dynamic analysis. The number 

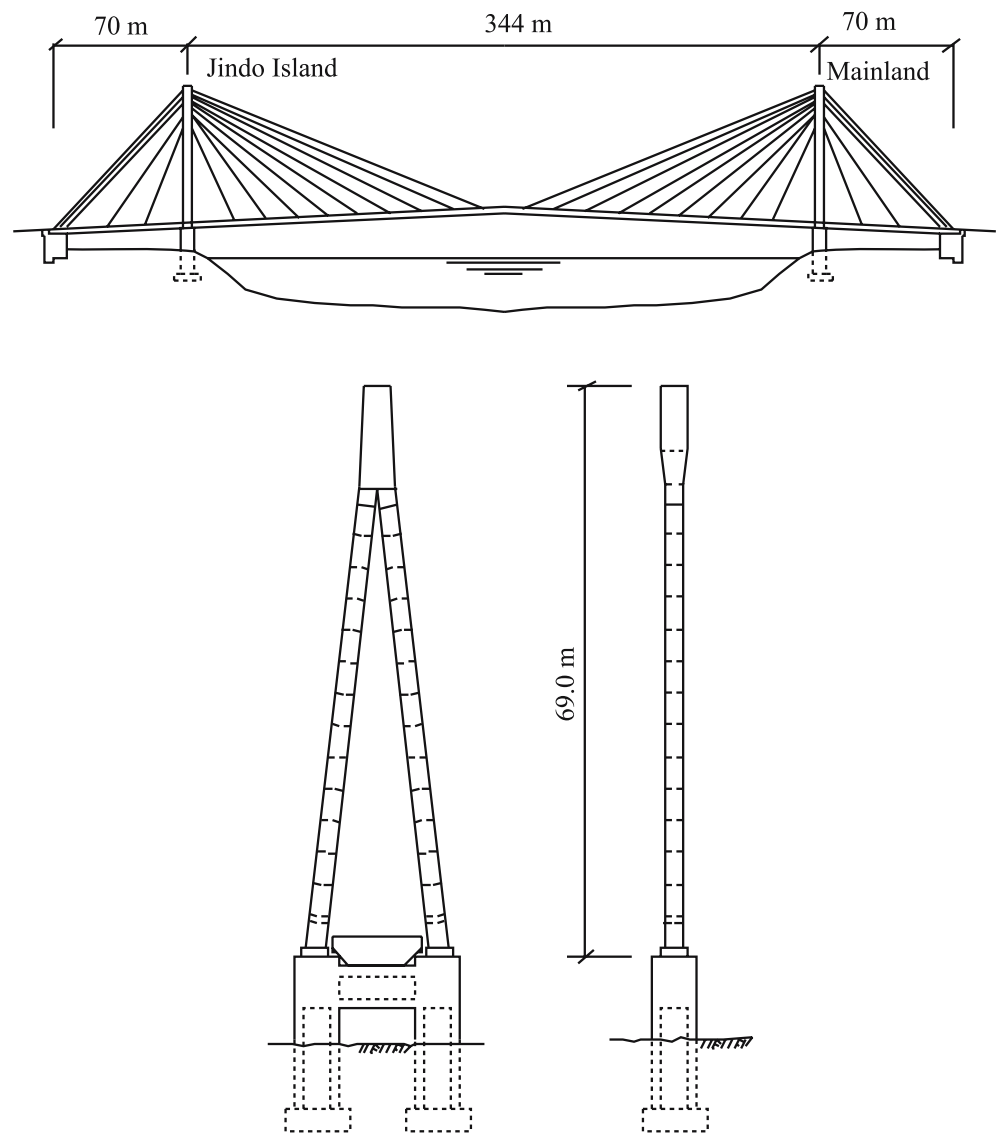

Figure 2. General arrangements of Jindo Bridge (Tappin \& Clark 1985).

Table 1. Structural material and sectional properties for Jindo Bridge.

\begin{tabular}{|c|c|c|c|c|c|}
\hline Members & & $\begin{array}{c}\text { Elastic modulus } \\
\left(\mathrm{kN} / \mathrm{m}^{2}\right)\end{array}$ & $\begin{array}{l}\text { Mass density } \\
\left(\mathrm{kg} / \mathrm{m}^{3}\right)\end{array}$ & $\begin{array}{l}\text { Cables sectional } \\
\text { area }\left(\mathrm{m}^{2}\right)\end{array}$ & $\begin{array}{l}\text { Damping } \\
\text { ratio }\end{array}$ \\
\hline Deck & Steel & $2 \cdot 1 \times 10^{8}$ & $8800 \sim 15700$ & $\begin{array}{c}0.416 \sim 0.827 \\
0.02010\end{array}$ & $2 \%$ \\
\hline \multirow{2}{*}{ Cables } & Steel & $1.5 \times 10^{8}$ & 7850 & $\begin{array}{c}0 \cdot 01004 \\
0 \cdot 00756 \\
0 \cdot 00556 \\
0 \cdot 00428\end{array}$ & $2 \%$ \\
\hline & CFRP & $1.125 \times 10^{8}$ & 1600 & $\begin{array}{l}0.0268 \\
0 \cdot 0134 \\
0 \cdot 0101 \\
0.0074 \\
0.0057\end{array}$ & $5 \%$ \\
\hline
\end{tabular}


of modes play a very important role in obtaining the results with acceptable accuracy. So, the first 15 modes of vibration are adopted for the response calculations.

To investigate the dynamic responses of the Jindo Bridge, two-dimensional mathematical model is used for calculations in figure 2. It has been shown that a two-dimensional analysis of the cable-stayed bridge provides natural frequencies and mode shapes which are in close agreement with those obtained by three-dimensional analysis (Garevski et al 1988). The nonlinearity of the inclined cable stays is considered with equivalent modulus of elasticity. The nonlinearity of the cable stays originates with an increase in the loading followed by a decrease in the cable sag. To overcome this nonlinear effect of the proposed equivalent modulus of elasticity, which includes the normal modulus of elasticity, the effect of sag and tension load, is employed. The equivalent modulus of elasticity was given by (Troitsky 1988):

$$
E_{i}=\frac{E}{1+\left(\gamma^{2} L^{2} E / 12 \sigma^{3}\right)}
$$

where, $E$ is the modulus of elasticity of the straight cable, $L$ is the horizontal length of the cable, $\gamma$ is specific weight of the cable and $\sigma$ is the tensile stress in the cable.

The respective expectation and correlation function for the elastic modulus $E_{\rho}$ are assumed as follows:

$$
\begin{aligned}
& \mathrm{E}_{\mathrm{STEEL}}\left[E_{\rho}\right]=1.5 \times 10^{8} \quad \lambda=10, \\
& E_{\mathrm{CFRP}}\left[E_{\rho}\right]=1.125 \times 10^{8} \\
& \alpha_{\text {Steel }}=0.10 \text { and } \alpha_{\mathrm{CFRP}}=0.15, \\
& \mu\left(E_{\rho}, E_{\sigma}\right)=\exp \left(-\frac{\left|x_{\rho}-x_{\sigma}\right|}{\lambda l}\right),
\end{aligned}
$$

where $x_{\rho}, l$ and $\lambda$ are ordinates of the element midpoints, structural member length and decay factor. The cable-stayed bridge is modelled by 169 stochastic finite elements with different lengths. MCS method is simulated for 10000 simulations.

Natural frequencies, the mean of maximum displacements and internal forces of the Jindo Bridge using either CFRP or steel stay cables are calculated according to perturbation-based SFEM, in which geometrical nonlinearity is considered. The efficiency and accuracy of the proposed algorithm are validated by comparison with results of MCS method.

The first 15 modes of the bridge using either CFRP or steel stay cables are computed by the perturbation-based SFEM analysis. Table 2 shows the modal properties of the bridge. As CFRP cables are used, the natural frequencies of all modes are increased by less than $3 \%$ as compared to the case of steel cables. The fact can be mainly attributed to the decreasing of structural mass. Because the CFRP cable is designed by the principle of equivalent axial stiffness, structural stiffness under the two cases is almost the same, but the mass density CFRP stay cables is only 0.204 times that of the steel stay cables as shown in table 1 . With the same stiffness and much lower mass, the natural frequencies are therefore increased. The adoption of CFRP stay cables has the effect of stiffening the structure by increasing its natural frequencies.

Firstly, the accuracy of perturbation-based SFEM is tested with MCS method. For this aim, these two methods are compared with each other for the mean of maximum vertical displacement values in figure 3 and table 3. By comparing perturbation-based SFEM and MCS methods, for both CFRP and steel stay cables, these two methods gives closer results 
Table 2. Effects of cable materials on structural natural frequencies $(\mathrm{Hz})$ for Jindo Bridge.

\begin{tabular}{lcc}
\hline & \multicolumn{2}{c}{ Frequencies $(\mathrm{Hz})$} \\
\cline { 2 - 3 } Mode No. & Steel & CFRP \\
\hline 1 & 0.4441 & 0.4471 \\
2 & 0.6422 & 0.6482 \\
3 & 0.9486 & 0.9556 \\
4 & 1.2672 & 1.2778 \\
5 & 1.5928 & 1.6041 \\
6 & 1.8273 & 1.8405 \\
7 & 1.9618 & 1.9822 \\
8 & 2.0316 & 2.0501 \\
9 & 2.3723 & 2.3874 \\
10 & 2.7694 & 2.7977 \\
11 & 2.9026 & 2.9225 \\
12 & 2.9450 & 2.9614 \\
13 & 3.6545 & 3.6743 \\
14 & 4.3131 & 4.4717 \\
15 & 4.4601 & 4.6068 \\
\hline
\end{tabular}

to each other. The average absolute differences between these two methods for vertical displacement values using steel stay cables are about $4.65 \%$, however, average differences using CFRP stay cables are about $4.54 \%$. It is also seen from figure 3 that in the case of CFRP stay cables, the vertical displacements are increased as compared to the case of steel stay cables. The average difference between these two materials for the vertical displacement value is about $0.95 \%$.

The mean of maximum shear forces and bending moments for deck of the Jindo Bridge are presented in figure 4. It is seen from figure 4 that values obtained from using either steel or CFRP stay cables is closed to each other. The minimum differences between the shear forces and bending moments of these two materials are $0.14 \%$ and $0.59 \%$, respectively. The average

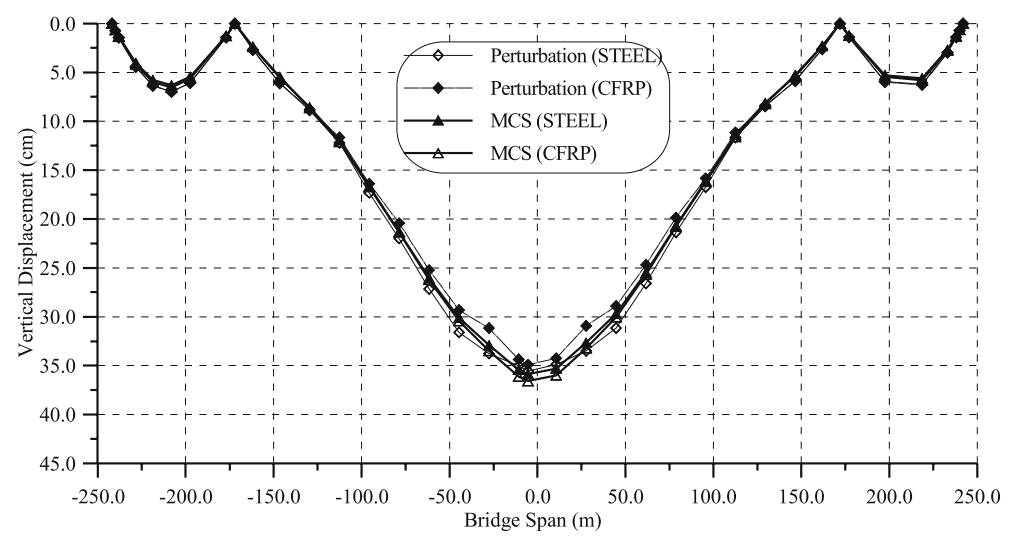

Figure 3. The mean of maximum vertical displacements at the deck of Jindo Bridge for random elastic module. 
Table 3. Structural material and sectional properties for Fatih Sultan Mehmet Bridge.

\begin{tabular}{|c|c|c|c|c|c|}
\hline Members & & $\begin{array}{l}\text { Elastic modulus } \\
\qquad\left(\mathrm{kN} / \mathrm{m}^{2}\right)\end{array}$ & $\begin{array}{c}\text { Mass density } \\
\left(\mathrm{kg} / \mathrm{m}^{3}\right)\end{array}$ & $\begin{array}{c}\text { Cables sectional } \\
\text { area }\left(\mathrm{m}^{2}\right)\end{array}$ & $\begin{array}{l}\text { Damping } \\
\text { ratio }\end{array}$ \\
\hline Deck & Steel & $2.05 \times 10^{8}$ & 9980 & $1.26 \sim 2.68$ & $2 \%$ \\
\hline \multirow{2}{*}{ Hanger } & Steel & $1.93 \times 10^{8}$ & 7985 & 0.7376 & $2 \%$ \\
\hline & CFRP & $1.45 \times 10^{8}$ & 1653 & $1 \cdot 043$ & $5 \%$ \\
\hline \multirow{2}{*}{ Cable } & Steel & $1.93 \times 10^{8}$ & $7850 \sim 7994$ & $\begin{array}{l}0.6904 \\
0.0088\end{array}$ & $2 \%$ \\
\hline & CFRP & $1.45 \times 10^{8}$ & $1544 \sim 1661$ & $\begin{array}{l}0.976 \\
0.0241\end{array}$ & $5 \%$ \\
\hline
\end{tabular}

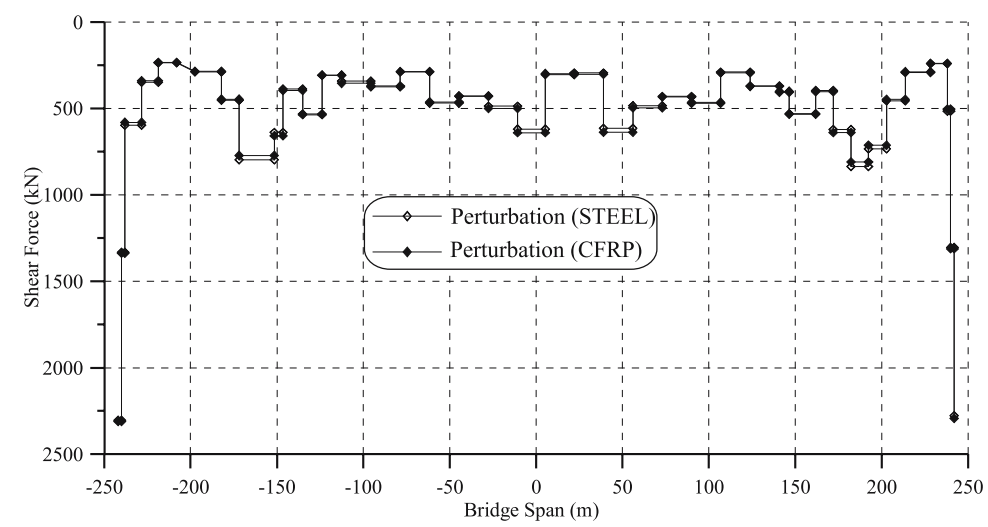

(a)

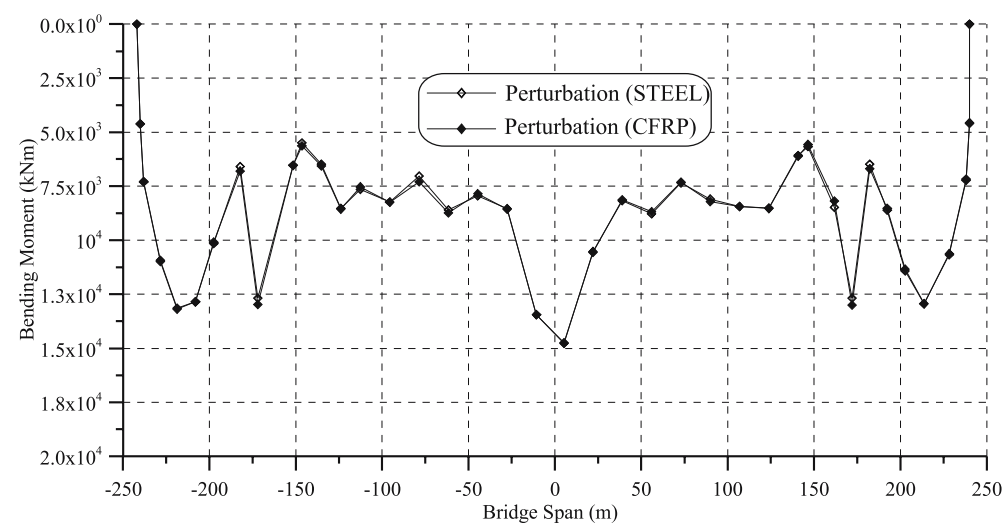

(b)

Figure 4. The mean of maximum shear forces (a) and bending moment (b) for deck of Jindo Bridge for random elastic module. 
differences for these internal forces are about $0.7 \%$ and $1.01 \%$, respectively. The mean of maximum values acquired by steel stay cables are generally smaller than those calculated by the CFRP stay cables. It is concluded from the above analysis that the using of CFRP cables in long-span cable-supported bridges is feasible.

\subsection{Example 2. Suspension bridge}

The Fatih Sultan Mehmet (Second Bosporus) Suspension Bridge is chosen as second example to demonstrate the response variation of CFRP and steel cables bridges. The bridge connecting the Europe and Asia Continents in Istanbul, Turkey has a box girder deck with $39.4 \mathrm{~m}$ wide overall and $1090 \mathrm{~m}$ long. There are no side spans and the steel towers $110 \mathrm{~m}$ above ground level. The hangers are vertical and connect to the deck and cable with singly hinged bearing. The horizontal distance between the cables is $33.8 \mathrm{~m}$ and the roadway is $28 \mathrm{~m}$ wide, accommodating two four-lane highways. The roadway at the mid-span of the bridge is approximately $64 \mathrm{~m}$ above the sea level. General arrangement of the bridge is shown in figure 5. To investigate stochastic dynamic responses of the bridge model, 2D mathematical model is considered as shown in figure 5. Dumanoglu \& Severn (1990) verified that 2D analysis provide natural frequencies and mode shapes which are in close agreement with those obtained by 3D analysis in the vertical direction for suspension bridges. As the deck, towers, and cables of the selected bridge are modelled by beam elements; the hangers are modelled by truss elements. A finite element model of the bridge with 128 nodal points, 142 beam elements and 44 truss elements are used in the analyses. This model has three degrees of freedom at each nodal point, namely, two translational degrees of freedom in vertical and longitudinal axes and one rotational degree of freedom in lateral axis. So, the finite element model of the bridge is decreased to 382 degrees of freedom and therefore a $2 \mathrm{D}$ analysis is adopted in the vertical plane of the bridge. In addition, structural material and sectional properties of the steel and CFRP cables are presented in table 3.

The suspension bridge is modelled by 186 stochastic finite elements of different length. The respective expectation and correlation function for the elastic modulus $E_{\rho}$ are assumed as follows:

$$
\begin{aligned}
& E_{\mathrm{STEEL}}\left[E_{\rho}\right]=2.05 \times 10^{8} \quad \lambda=10 \\
& E_{\mathrm{CFRP}}\left[E_{\rho}\right]=1.45 \times 10^{8} \\
& \mu\left(E_{\rho}, E_{\sigma}\right)=\exp \left(-\frac{\left|x_{\rho}-x_{\sigma}\right|}{\lambda l}\right) .
\end{aligned}
$$

Damping ratio $2 \%$ is used for the steel bridge model, $5 \%$ damping ratio is utilized for the CFRP composite bridge model through the stochastic dynamic analysis. The first 20 modes of vibration are adopted for the response calculations.

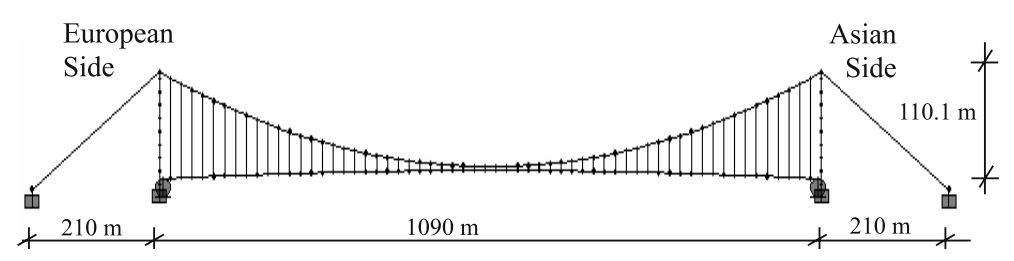

Figure 5. 2D finite element model of Fatih Sultan Mehmet suspension bridge. 
Table 4. Effects of cable materials on structural natural frequencies $(\mathrm{Hz})$ for Fatih Sultan Mehmet bridge.

\begin{tabular}{lcc}
\hline & \multicolumn{2}{c}{ Frequencies (Hz) } \\
\cline { 2 - 3 } Mode No. & Steel & CFRP \\
\hline 1 & $0 \cdot 1194$ & $0 \cdot 1250$ \\
2 & $0 \cdot 1539$ & 0.1667 \\
3 & 0.2076 & 0.2453 \\
4 & 0.2395 & $0 \cdot 2532$ \\
5 & 0.3127 & 0.3371 \\
6 & 0.3867 & 0.4203 \\
7 & 0.4717 & 0.5199 \\
8 & 0.5376 & 0.5995 \\
9 & 0.5635 & 0.6289 \\
10 & 0.6653 & 0.7511 \\
11 & 0.7757 & 0.8850 \\
12 & 0.8966 & 1.0322 \\
13 & 1.0268 & 1.1921 \\
14 & 1.1682 & 1.3355 \\
15 & 1.2250 & 1.4221 \\
\hline
\end{tabular}

For the geometrical nonlinearity in forming the stiffness matrix $\left(\left[K_{\alpha \beta}^{0}\right]\right)$, geometric stiffness matrix $\left(\left[K_{g}\right]\right)$ is added to the elastic stiffness matrix $\left(\left[K_{e}\right]\right)$ (Przemieniecki 1968).

$$
\left[K_{\alpha \beta}^{0}\right]=\left[K_{e}\right]+\left[K_{g}\right] .
$$

Stochastic dynamic response of the suspension bridge using either CFRP or steel cables is computed by perturbation-based SFEM for random elastic module, which the structural geometrical nonlinearity is also considered.

As CFRP cables are used, the natural frequencies of all modes are increased by less than $15 \%$ according to the steel cables as given in table 4 . The fact can be mainly attributed to the decreasing of structural mass. Because the CFRP cable is designed by the principle of equivalent axial stiffness, structural stiffness for the two cases is almost the same. With the same stiffness and much lower mass density, structural natural frequencies are therefore increased. The adoption of CFRP cables in the Fatih Sultan Mehmet Bridge has the effect of stiffening the structure by increasing its natural frequencies.

The accuracy of perturbation-based SFEM is tested with MCS method for the mean of maximum vertical displacement values as shown in figure 6 . If comparing perturbation-based SFEM and MCS method, for both CFRP and steel cables, these two methods gives closer results to each other. The average absolute differences between these two methods for vertical displacement values using steel stay cables are about 3.37\%, however, average differences using CFRP cables are about $9.01 \%$. It is also can be seen from figure 6 that in the case of CFRP cables, as compared to the case of steel cables the vertical displacements on the deck for Fatih Sultan Mehmet Bridge increase. The average difference between these two materials for the vertical displacement value is about $8 \%$.

The mean of maximum shear forces and bending moments for the bridge deck calculated using perturbation-based SFEM dynamic analyses are shown in figure 7. It is seen from figure 7 that stochastic values acquired from using CFRP cables are closed to the ones using steel cables. The average differences between the shear forces and bending moments of these 


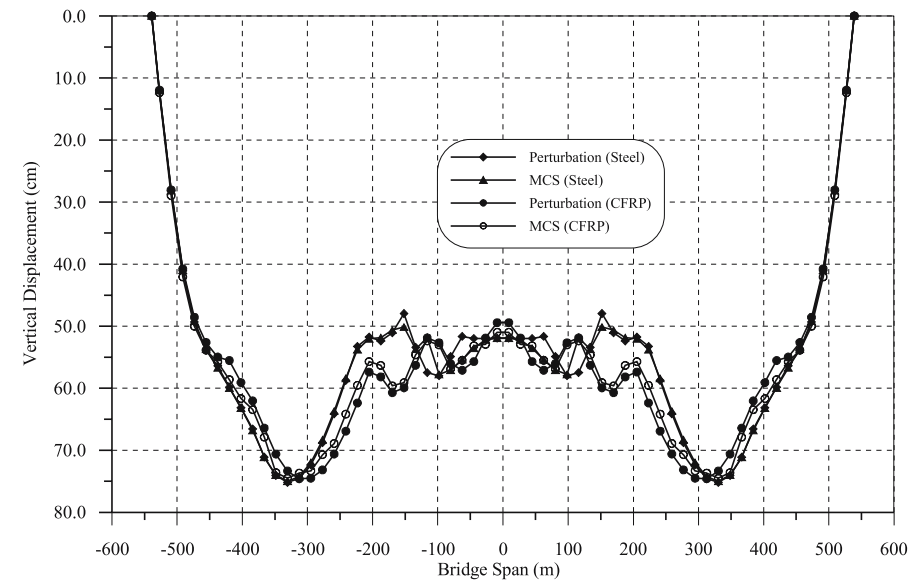

Figure 6. The mean of maximum vertical displacements at the deck of Fatih Sultan Mehmet Bridge for random elastic module.

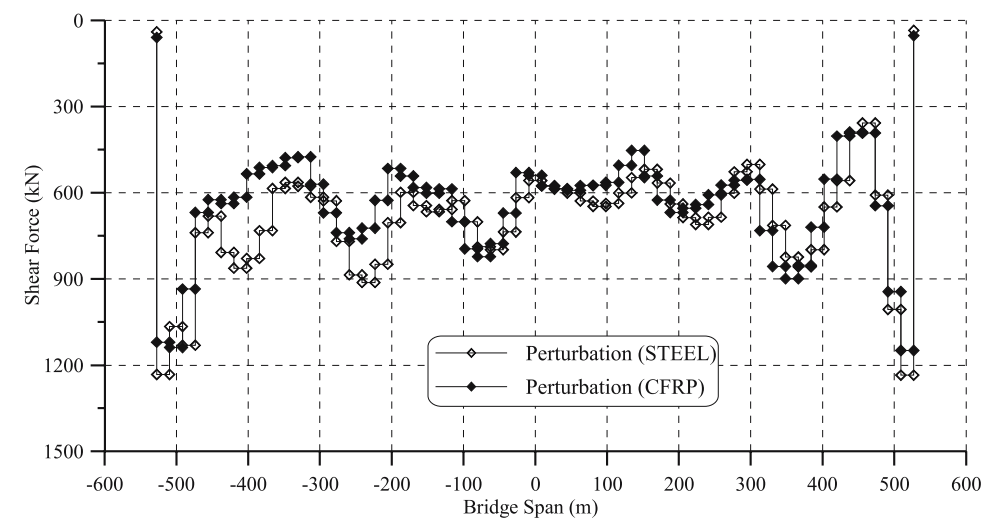

(a)

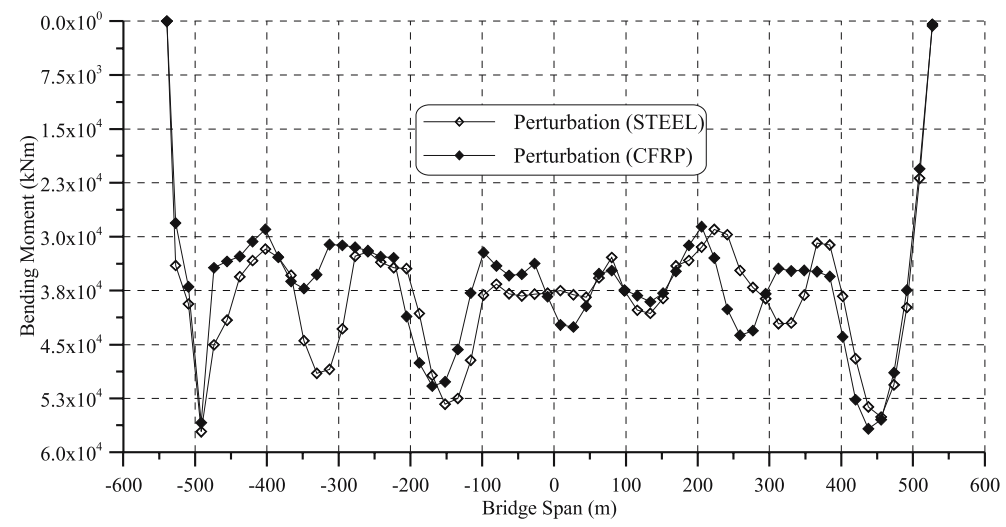

(b)

Figure 7. The mean of maximum shear forces (a) and bending moment (b) for deck of Fatih Sultan Mehmet Bridge for random elastic module. 
two materials are $12.23 \%$ and $10.36 \%$, respectively. The mean of maximum values of internal forces obtained from using steel cables are generally higher than the maximum values obtained using CFRP cables.

In addition to the results obtained from these two examples; for the analysis of Jindo Bridge (figure 2), it needs about 2 minutes for perturbation based stochastic analysis. However, it needs about 8 hours for MCS analysis with the PC which have Intel Pentium (R) $2.40 \mathrm{GHz}$ CPU and $768 \mathrm{MB}$ RAM. On the other hand, it needs about 3 minutes for perturbation based stochastic analysis, using either CFRP or steel cables and needs about 11 hours for MCS analysis for Fatih Sultan Mehmet Bridge (figure 5).

\section{Conclusions}

In this paper, a cable-stayed bridge using CFRP stay cables and a suspension bridge using CFRP cables and hangers are schemed, in which the cable's cross sectional area is determined by the principle equivalent axial stiffness. The stochastic seismic behaviours of two bridges using either CFRP or steel cables are investigated by perturbation-based SFEM and MCS methods. Some conclusions drawn from this study are:

- It is seen that the results obtained from SFEM and MCS methods for CFRP and steel cables are close to each other.

- The fundamental frequencies of the bridges with CFRP cables are relatively high due to its light weight and high strength.

- The mean of maximum values of displacements and internal forces acquired by steel cables are generally smaller than those calculated by the CFRP cables.

- Based on the stochastic seismic analyses results, it seems that the proposed CFRP cables and hangers cross-sections are adequate for the serviceability of long-span bridges.

- For long-span bridges having the same span length and the same cable arrangement type, the replacement of the conventional steel cables with the light weight, high strength CFRP cables and hanger helps to enhance the rigidity of the structures.

- The SFEM, based on the perturbation technique, offers an efficient alternative to the MCS method.

\section{References}

Adhikari S, Friswell M I 2007 Random matrix eigenvalue problems in structural dynamics. Int. J. Numerical Methods Eng. 69(3): 562-591

Adhikari S, Manohar C S 2000 Transient dynamics of stochastically parametered beams. J. Eng. Mech. 126(11): 1131-1140

Almansour H H 2006 The performance of hybrid long-span cable stayed bridges using advanced composites. Ph.D. Thesis, Department of Civil Engineering, The University of Ottowa

Aparicio A C, Casas J R 1997 The Alamillo cable-stayed bridge: Special issues faced in the analysis and construction. Proceedings of the Institution of Civil Engineers-Structures and Buildings 122(4): $432-450$

Brunner A J 2000 Experimental aspects of Mode I and Mode II fracture toughness testing of fibrereinforced polymer-matrix composites. Comput. Methods Appl. Mech. Eng. 185(2-4): 161-172

Cheng S 1999 Structural and aerodynamic stability analysis of long-span cable-stayed bridges. Ph.D. Thesis, Department of Civil and Environmental Engineering, The University of Ottowa 
Cheng J, Xiao R C 2005 Probabilistic free vibration and flutter analyses of suspension bridges. Eng. Struct. 27(10): 1509-1518

Çavdar Ö, Bayraktar A, Çavdar A, Adanur S 2008 Perturbation-based stochastic finite element analysis of the structural systems with composite sections under earthquake forces. Steel and Composite Structures 8(2): 129-144

Dumanoglu, A.A. and Severn, R.T. 1990 Stochastic response of suspension bridges to earthquake forces. Earthquake Eng. and Structural Dynamics 19(1): 133-152

Falsone G, Impollonia N 2002 A new approach for the stochastic analysis of finite element modelled structures with uncertain parameters. Comput. Methods Appl. Mech. Eng. 191(44): 5067-5085

Garevski M, Dumanoglu A A, Severn R T 1988 Dynamic characteristics and seismic behaviour of Jindo Bridge, South Korea. Struct. Eng. Rev. 1: 141-149

Khalifa M A 1992 Dynamic vibration of cable-stayed bridges using carbon fibre composite cables. Proceedings of the CSCE 1st International Conference on Advanced Composite Materials in Bridges and Structures, Canada, August

Kleiber M, Hien T 1992 The stochastic finite element method (New York, USA: John Wiley and Sons)

Kremmidas S C 2004 Improving bridge stay cable performance under static and dynamic loads. Ph.D. Thesis, Department of Structural Engineering, The University of California, San Diego

Liu C H, Wang T L, Qin Q 1999 Study on sensitivity of modal parameters for suspension bridges. Struct. Eng. Mech. 8(5): 453-464

Melchers R E 1999 Structural reliability analysis and prediction (England: John Wiley \& Sons)

Meirer U 1999 The use of carbon fibre reinforced polymer (CFRP) cables in bridge engineering. Proceeding from the Techtextil Symposium, Frankfurt, April

Noisternig J F 2000 Carbon fibre composites as stay cables for bridges. Applied Composite Materials 7(2-3): 139-150

PEER (Pacific Earthquake Engineering Research Centre) 2007 http://peer.berkeley.edu/smcat/data

Przemieniecki J S 1968 Theory of matrix structural analysis (New York: Mcgraw-Hill Book Company)

Shinozuka M 1972 Monte carlo simulation of structural dynamics. Computers and Structures 2(5-6): $865-874$

Tappin R G R, Clark P J 1985 Jindo and Dolsan bridges: design. Proc. Inst. Civil Eng. 78(6): 1281-300

Troitsky M S 1988 Cable-stayed bridges, (London: BSP Professional Books, Second edition)

Zhang Y, Cai C S 2007 Load distribution and dynamic response of multi-girder bridges with FRP decks. Eng. Struct. 29(8): 1676-1689

Zhang X J, Ying L D 2007 Wind-resistant performance of cable-supported bridges using carbon fibre reinforced polymer cables. Wind and Structures 10(2): 121-133

Zhang J, Ellingwood B 1996 SFEM for reliability of structures with material nonlinearities. J. Struct. Eng. ASCE 122(6): 701-704

Zhu W Q, Wu W Q 1992 A stochastic finite element method for real eigenvalue problem. Probabilistic Eng. Mech. 118(3): 496-511 